\title{
Die plantgemeenskappe van die Ba-landtipe in die Mooirivieropvanggebied, Transvaal
}

\author{
H. Bezuidenhout* \\ Binnelandse Nasionale Parke, Posbus 2696. Kimberley 8300 \\ G.J. Bredenkamp \\ Departement Plantkunde, Universiteit van Pretoria. Pretoria (00)।
}

Ontiams $28 \mathrm{Mei} 1990$; anmaar 7 Nosember 1990

\section{UITTREKSEI.}

Die doel van hierdie studie was om hoofplantegroei-eenhede en hulle variasies - van die Ba-landripe - te identifiseer, karakteriseer en an die hand van die habitat ekologies te interpreteer. Ses plantgemeenskappe is deur toepassing van 'n numeriese klassifikasie (TWINSPAN) en Brann-Blanquet-prosedures geidentifiseer en elk is met 'n spesifieke habitat gekorreleer: 'n Daidelike onderskeid is tussen die hoogliggende en die laagliggende plantgemecnskappe gemaak. Plamegroeigradiënte en geassosieerde gradiënte in habitat is deur toepassing van 'n ordeningstegniek (DECORANA) geidentifiseer. Die studie beklemtoon die belangrikheid van topografie en grondtipe vir dic afbakening van plantegroei-bestumrsecenhede vir boerdery of natuurbewaring.

\section{ABSTRACT}

\section{Classification of the vegetation of the Ba land type in the Mooi River catchment area, Transtaal}

The aim of this study was to identifi, characterize and interpret ecologically, by using habitat characteristic's, the major vegelation units and their variations of the Ba land type. Six plant communities were successfully distinguished through applying a mumerical classification (TWINSPAN) and Braun-Blanquet procedures. The plant communities could easily be correlated with specific habitat types. A clear distinction could be made between plant communities of the upland and lowland areas. Vegetation gradients and associated gradients in habitat were identified by using an ordination technique (DECORANA). The study emphasized the importance of topography and soil type for the delimitation of management anits for farming or nature conservation practices.

\section{INLEIDING}

'n Gebrek aan kennis oor die plantegroei van die grasveldbioom het gelei tot die inisiëring van die grasveldbioonsprojek.' As deel van hierdie projek is 'n aantal navorsingsprogramme in die westelike decl van die grasveldbioom geïnisicer en uitgevoer. ${ }^{3+}$ en 5

Daar is min oor die plantegroei van die Ba-landtipe bekend. Louw" bied 'n oorsigtelike verslag oor die plantegroei van die Potchefstroom-gebied aan. Volgens Acocks'2 se klassifikasie verteenwoordig die gebied die sentrale variasie van die Bankenveld. Die behoefte om die hoof- en subplantegrocitipes wat in die grasveldbioom aangetref word te identifiseer en om die ligging, omvang en habitatskenmerke van elke tipe te bepaal, word telkens beklemtoon. ${ }^{1.23}$

Om sinvolle aanbevelings oor veldbestuurspraktyke en beplanning te kan maak, is dit noodsaaklik dat 'n grondige kennis van die ekologie van die gebied verkry word. ${ }^{\circ}$ Die daarstelling van relatief homogene plantegroei-cumhabitat-eenhede behoort ook 'n wetenskaplik gebascerde riglyn vir die afbakening van veldbestuurseenhede te verskaf.

Verder, weens die feit dat die natuurlike plantegroei van die Ba-landtipe tot 'n groot mate deur die maak van lan derye vernietig is, en voortbestaan van verteenwoordigende plantgemeenskappe dus bedreig is, behoort 'n studie van die plantegroei van hierdie landtipe lig op die identifikasic van moontlike bewaringsgebiede te werp. Van besondere belang is dat hierdic ondersoek deel uitmaak van 'n uitgebreide sintese van die plantegroei van die grasveldbiom, wat daartoe sal lei dat 'n formele, omvattende hiërargiese sintaksonomie opgestel kan word., 24, 25 So 'n sintese sal 'n bydrae tot fitososiologie in Suider-Afrika lewer. Die plantegroei van die A-landtipe in die Mooirivieropvanggebied is reeds geklassifiseer en beskryf. "' In hierdic verslag word die klassifikasic, beskrywing en ekologiese interpretasie van die Ba-landtipe aangebied.

\section{STUDIEGEBIED}

Die ligging van die A-landtipe in die Mooirivieropvanggebied word in figuur 1 aangedui. Uit 'n fitososiologiese studie van die Moorivieropvanggebied' het dit geblyk dat die plantegroei van die landtipes in ' $n$ mindere of meerdere mate van mekaar verskil. Die Landtipe-opnamepersoneel' definieer 'n landtipe as 'n eenheid wat 'n gebied verteenwoordig op 'n skaal van 1:250 000, wat eenvormig is ten opsigte van terreinvorm, grondpatrone en klimaat. Die Ba-landtipe beslaan ongeveer 84750 hektaar en is tussen 1440 en $1600 \mathrm{~m}$ bo seespicël geleë. ${ }^{2}$ Die Ba-landtipe 


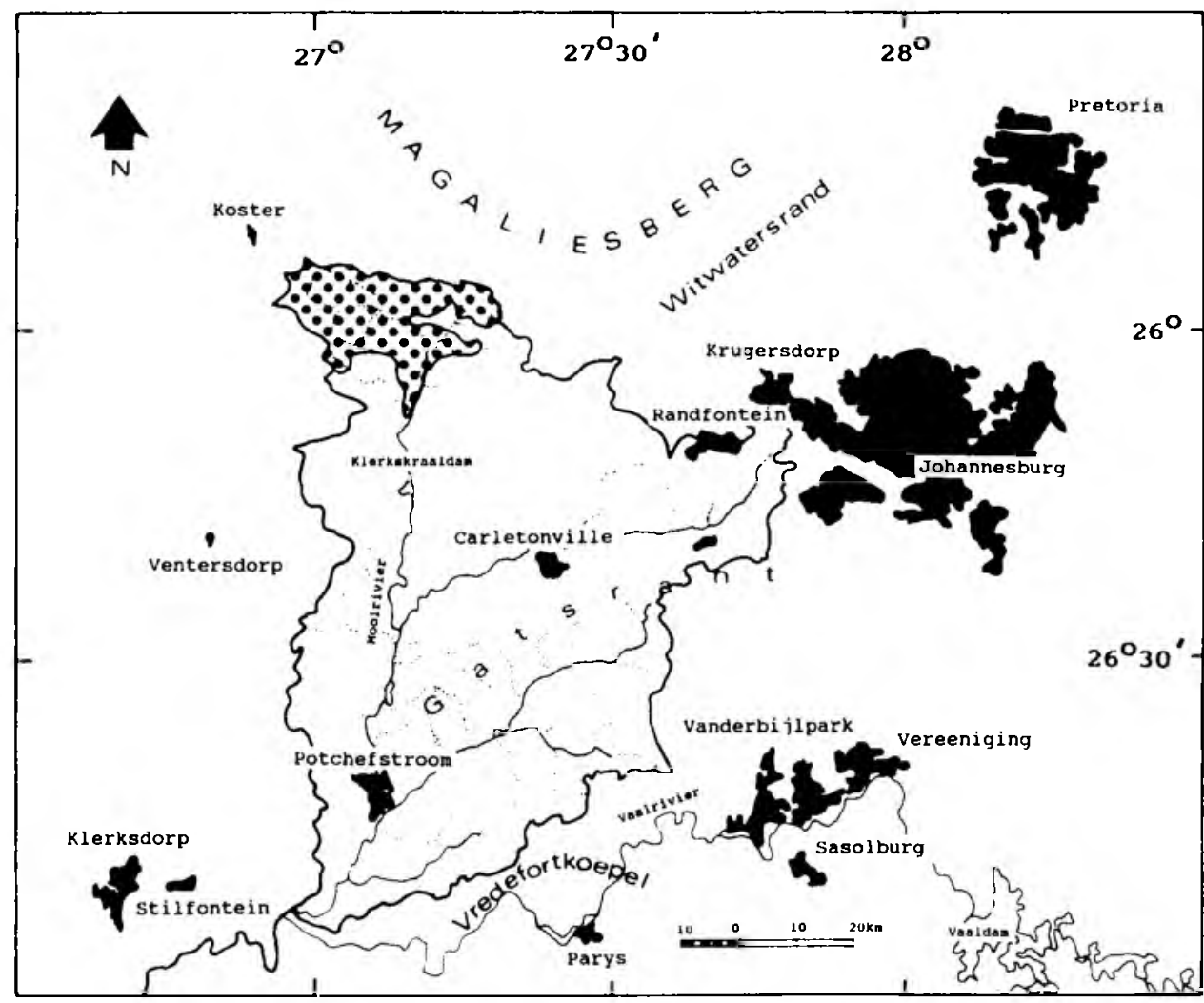

FIGUUR I: Die ligging van die studiegebied (kolletjies) in die Mooirivieropvanggebied.

word hoofsaaklik deur skalies, leie, kwartsiete en Hekpoortlawa van die Pretoria Groep (Transvaal Opeenvolging) onderlê. Die grondtipe wat in die Ba-landtipe voorkom, is rooi of geel, distrofies en/of mesotrofies en apedaal (struktuurloos). ${ }^{2}$ Op die relaticwe hoogliggende gebiede is die Hutton-, Glenrosa- en Mispahgrondvorms ${ }^{16}$ dominant. Die Hutton-, Clovelly- en Glencoegrondvorms is die dominante grondtipe teen die middelhange, wat meestal vir akkerbou aangewend word. Hierdie grondtipe is dikwels geploeg en gevolglik is die natuurlike plantegroei meestal tot vlakker, klipperige grond beperk. Die vloedvlaktes word deur die Westleigh-, Clovelly- en Glencoegrondvorms verteenwoordig, terwyl die dominante grondtipe in die waterbane, die Rensburgvorm is. ${ }^{2}$

Volgens Köppen se klassifikasiesisteem word die gebied as 'n CW-klimaat - dit is 'n warm, gematigde klimaat met somerreëns - beskryf. ${ }^{7}$ Groot klimaatskontraste tussen somer en winter en uiterstes soos droogtes, oorstromings, hael en ryp is kenmerkend van die streek. ${ }^{8}$ Die gemiddelde jaarlikse reënval (aangeteken oor ten minste vyftig jaar) varieer nie aansienlik nie, naamlik vanaf $656,7 \mathrm{~mm}$ by Koster, $653,7 \mathrm{~mm}$ by Magaliesburg tot $639,9 \mathrm{~mm}$ by Boons. ${ }^{9}$ Gedurende die somermaande, veral Januarie en Desember, is die gemiddelde daaglikse maksimum temperature tot $30,6^{\circ} \mathrm{C}$, terwyl die lae gemiddelde daaglikse minimum temperature van tot $-1,8^{\circ} \mathrm{C}$ in die wintermaan$\mathrm{de}^{\mathrm{y}}$ duidelik die temperatuuruiterstes wat oor ' $\mathrm{n}$ jaar aangeteken is, aantoon.

\section{METODES}

In 'n plantegroeiklassifikasie-navorsingsprogram ${ }^{5}$ is landtipe-eenhede' gebruik as eerste stratifisering van die Mooirivieropvanggebied, met die doel om die plantegroei doeltreffend te monster. In hierdie omvattende studie is vyf landtipes onderskei. Monsterpersele is pro-rata op 'n areagroottebasis tussen die landtipes verdeel.

Natuurlike plantegroei is op die Ba-landtipe hoofsaaklik tot vlakker en/of klipperige, ongeploegde grond beperk. In hierdie Ba-landtipe is vier en twintig monsterpersele uitgeplaas. Binne die landtipe is die gebied verder gestratifiseer op grond van terreinvorm en homogene plantegroei, sodat alle ekotope ${ }^{18}$ waarop natuurlike plantegroei voorkom, verteenwoordigend gemonster is.

Die monsterpersele is ewekansig in die eenhede uitgeplaas. Plantegroei-opnames is volgens die BraunBlanquet-prosedure uitgevoer. ${ }^{13}$ 'n Volledige floristiese opname is in elke monsterperseel gemaak. Bedekkinggetalsterktewaardes ${ }^{14}$ is soos volg vir elke plantspesie wat in die perseel voorkom, aangeteken:

$\mathrm{R}$ - teenwoordig, maar nie volop nie, met 'n kroonbedekking van minder as $1 \%$ van die monsterperseeloppervlakte; + - volop, met 'n kroonbedekking van tussen $1 \%$ en $5 \%$ van die monsterperseeloppervlakte;

1 - enige aantal indiwidue met ' $n$ kroonbedekking van groter as $5 \%$ tot $12 \%$ van die monsterperseeloppervlakte; 2 - enige aantal indiwidue met 'n kroonbedekking van groter as $12 \%$ tot $25 \%$ van die monsterperseeloppervlakte; 3 - enige aantal indiwidue met 'n kroonbedekking van groter as $25 \%$ tot $50 \%$ van die monsterperseeloppervlakte; 4 - enige aantal indiwidue met 'n kroonbedekking van groter as $50 \%$ tot $75 \%$ van die monsterperseeloppervlakte; 5 - enige aantal indiwidue met ' $n$ kroonbedekking meer as $75 \%$ van die monsterperseeloppervlakte. Hierdie bedekkinggetalsterktewaardes vorm die matriks van tabel 1 .

Verder is ' $n$ gemiddelde hoogte en kroonbedekking van die boom-, struik- en kruidstratum addisioneel in die persele aangeteken. Die habitatopname sluit hoogte bo seespieël, tipe gesteente, aspek, persentasie klipperigheid van die grondoppervlak en ook grondtipe in. Meer inlig- 
ting oor die grondtipes is uit bestaande beskrywings ${ }^{2}$ verkry.

In 'n poging om sinvolle, ekologies verantwoorde plantgemeenskappe te onderskei, is die lloristiese datastel aan 'n numeriese klassifikasie, naamlik Tweerigtingspesieindikatoranalise (TWINSPAN) ${ }^{15}$ onderwerp. Die resultaat is deur die toepassing van die Braun-Blanquet-prosedure verfyn en die finale resultaat van die klassifikasie word as 'n fitososiologiese tabel aangebied. Die plantgemeenskappe wat onderskei is, is hierna aan die hand van die beskikbare habitatdata ekologies geinterpreteer. Met behulp van

TABEL 1

'n Fitososiologiese tabel van die Ba-landtipe in die Mooirivieropvanggebied

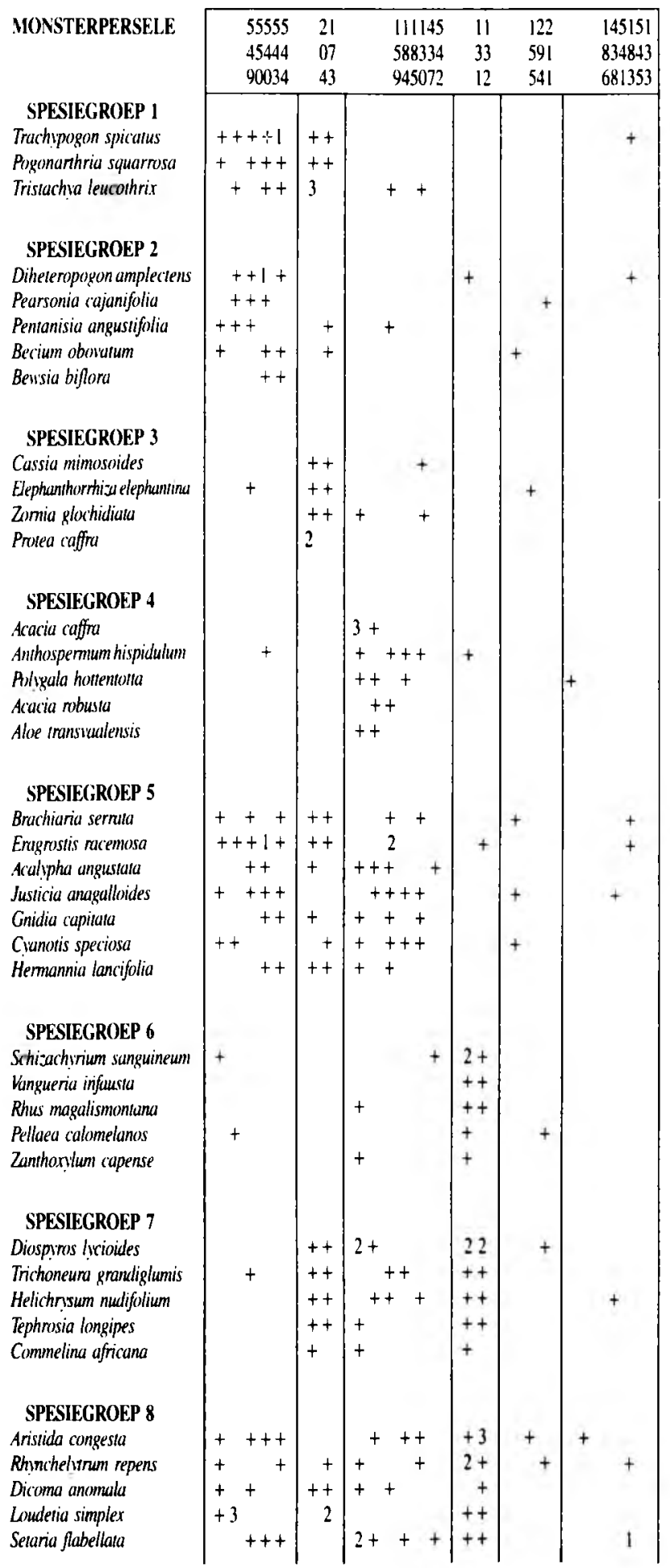

'n terreinvormskets word die ligging van die plantgemeenskappe in die landskap aangedui. Plantegroeigradiënte met geassosieerde gradiënte in habitat is deur middel van 'n indirekte gradiëntanalise, naamlik Ontneigde Ooreenstemminganalise (DECORANA) ${ }^{21}$ bepaal. Die name van taksons is in ooreenstemming met Gibbs-Russell et al. ${ }^{19,20}$ Daar is egter 'n onderskeid tussen Setaria flabellata Stapf. en Setaria sphacelata (Schumach.) Moss. gemaak. Hierdie twee taksons word in Gibbs-Russell et al. ${ }^{19}$ as 'n enkele spesie beskou. Die beskrywing van die plantgemeenskappe is in ooreenstemming met die Internasio-

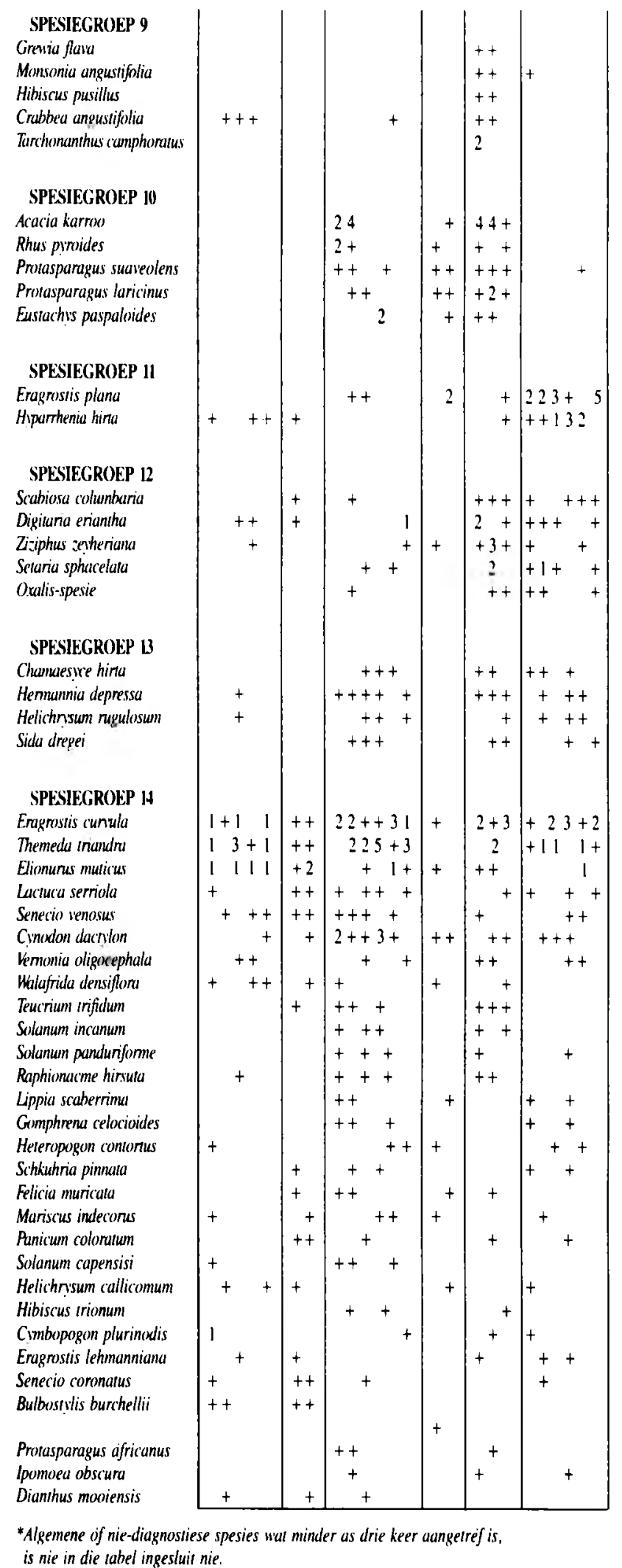


nale Kode van Sintaksonomie, 22 maar sintaksonrange word nie aan die gemeenskappe toegeken nie. weens te min fitososiologiese inligting oor die grasveld in die geheel.

\section{RESULTAAT}

\section{a. KLASSIFIKASIE}

Die plantegroei van die Ba-landtipe word as in Eragrostis curvula-Themeda triandra plantegroei-eenheid beskou.s Hierdie plantegroei-eenheid word deur spesiegroep 14 gekarakteriseer (tabel 1). Bome wat in die dic Ba-landtipe prominent is, is Acacia caffra, A. karroo en Diospyros lycioides. Algemene gras- en nic-grasagtige kruidspesies soos Eragrostis curvala, Themeda riandra, Eliomurus muticus, Cynodon dactylon, Lactuca serriola, Senecio venosus en Walafrida densiflora word algemeen in dié plantegroei-eenheid aangetref. Die ontleding van die floristiese data het tot die identifikasie van ses plantgemeenskappe gelei, wat op grond van twee hoof habitattipes geskei kan word. Hierdie onderverdeling van die plantegroei in relatief hoërliggende, droër gebiede en die relatief laerliggende vloedgebiede en valleivloere met waterbane word in die dendrogram (figuur 2) geïlustreer. Die volgende plantgemeenskappe is onderskei:

1.1 Die Loudetia simplex-Trachypogon spicatus-grasveld op die hoërliggende, goedgedreineerde gebiede.

1.1.1 Die Diheteropogon amplectens-Trachypogon spicatus-variant op hoogliggende, vlak, klipperige grond, wat gelykliggend en blootgestel is.

1.1.2 Die Trachypogon spicatus-Protea caffra-variant op hoogliggende, klipperige, goedgedreineerde grond teen glooiings, met groot, los rotsblokke op die oppervlak.

1.2 Die Diospyros lycioides - Acacia caffra-boomveld op middelhange (figuur $2 \mathrm{en} 3$ ) met diep grond $(>0,3 \mathrm{~m}$ ).

1.3 Die Schizachyrium sanguineum - Vangueria infaustastruikveld op kwartsiet dagsome.

1.4 Die Grewia flava - Acacia karroo-boomveld op dic laerliggende. swakgedreineerde vloedvlaktes.

1.5 Die Hyparthenia hirta - Eragrostis plana-grasveld in die laerliggende, swakgedreineerde waterbane.

b. BESKRYWING VAN DIE PLANTGEMEENSKAPPE

1.l Die Loudetia simplex - Trachypogon spicalusgrasveld.

Hierdie grasveld word op die hoërliggende (1 570 $1600 \mathrm{~m}$ bo seespieël), goedgedreineerde, klipperige gebiede aangetref (figuur 3). 'n Groot gedeelte van die natuurlike plantegroei van die Ba-landtipe word deur hierdie plantgemeenskap verteenwoordig. Diagnostiese spesies van hierdie grasveld (spesiegroep 1, tabel 1) is die grasse Trachypogon spicatus, Pogonarthria squarrosa en Tristachya leucothrix. Spesies van spesiegroepe $2,3,5,7,8$ en $14 \mathrm{kom}$ in die plantgemeenskap voor (tabel 1). Die dominante grondtipe waarmee dic gemeenskap geassosieer word, is die Mispah-, Glenrosa- en Huttongrondvorms. ${ }^{16}$ Twee variante is onderskei: naamlik die Diheteropogon amplectens-Trachypogon spicatus-variant en die Trachypogon spicatusProtea caffra-variant.

1.1.1 Die Diheteropogon amplectens-Trachypogon spicatus-variant.

Die habitat van dié variant is gelykliggend en blootgestel, met geen los rotsblokke op die grondoppervlak nic (figure 2 en 3). Diheteropogon amplectens, Pearsonia cajanifolia, Pentanisia angustifolia, Becium obovatum en Bewsia biflora is die diagnostiese spesies van die variant (spesiegroep 2, tabel 1). Spesies van spesiegroepe $1,5,8$ en 14 kom ook in dic variant voor.

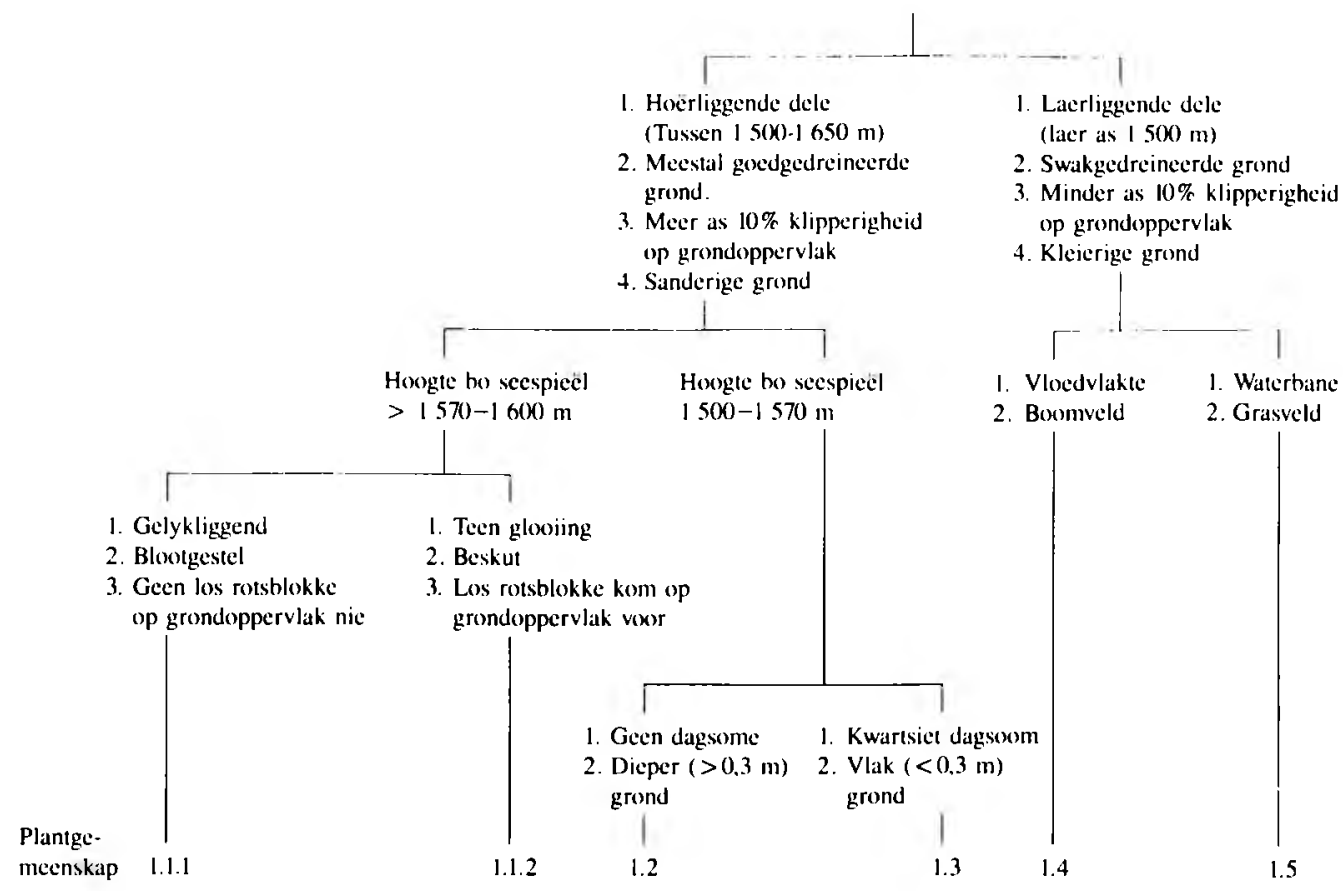

FIGUUR 2: 'n Ekologiese interpretasie van die plantgemeenskappe van die Ba-landtipe in die Mooirivieropvanggebied. 


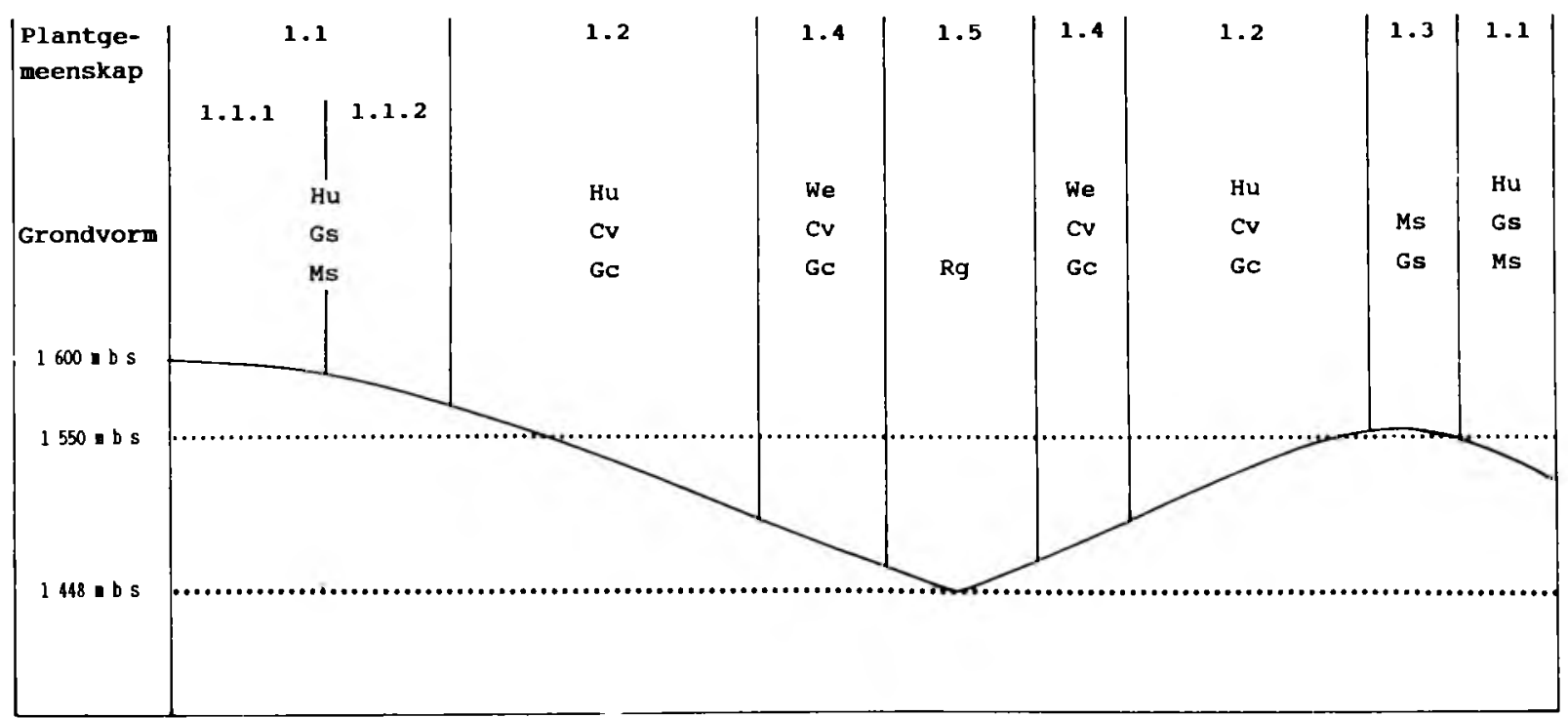

Plantgemeenskappe

1.1 Loudetia simplex-Trachypogon spicatus-grasveld

1.1.1 Diheteropogon amplectens-Trachypogon spicatus-variant

1.1.2 Trachypogon spicatus-Protea caffra-variant

1.2 Diospyros lycioides-Acacia caffra-boomveld

1.3 Schizachyrium sanguineum-Vangueria infausta $\rightarrow$ struikveld

1.4 Grewia flava-Acacia karroo-boomveld

1.5 Hyparrhenia hirta-Eragrostis plana-grasveld

\section{Grondvorm}

$\begin{array}{lll}\mathrm{Hu} & - & \text { Hutton } \\ \mathrm{Gs} & - & \text { Glenrosa } \\ \mathrm{Ms} & - & \text { Mispah } \\ \mathrm{Cv} & - & \text { Clovelly } \\ \mathrm{Gc} & - & \text { Glencoe } \\ \mathrm{We} & - & \text { Westleigh } \\ \mathrm{Rg} & - & \text { Rensburg }\end{array}$

FIGUUR 3: 'n Terreinvormskets van die Ba-landtipe met die posisie van die onderskeie plantgemeenskappe.

Hierdie grasveldvariant word gekenmerk deur die totale afwesigheid van bome en struike. Die kruidstratum is goed ontwikkeld met 'n gemiddelde hoogte van $0,75 \mathrm{~m}$ en gemiddelde kroonbedekking van $68 \%$. Die gemiddelde getal spesies per monsterperseel is 34. Prominente grasse wat in die variant aangetref word, is Trachypogon spicatus, Loudetia simplex, Diheteropogon amplectens, Tristachya leucothrix, Bewsia biflora, Brachiaria serrata, Setaria flabellata en Elionurus muticus. Die opvallende nie-grasagtige kruide is Pearsonia cajanifolia, Pentanisia angustifolia, Becium obovatum, Acalypha angustata, Justicia anagaloides, Hermannia lancifolia en Lactuca serriola.

1.1.2 Die Trachypogon spicatus-Protea caffra-variant.

Die Trachypogon spicatus-Protea caffra-variant kom teen glooiings voor en is dus meer beskut as die Diheteropogon amplectens-Trachypogon spicatus-variant. Groot, los rotsblokke word op die grondoppervlak aangetref (figure 2 en 3). Cassia mimosoides, Elephanthorrhiza elephantina, Zornia glochidiata en Protea caffra van spesiegroep 3 is die diagnostiese spesies in hierdie variant (tabel 1). Spesies van spesiegroepe 5, 7,8 en 14 word ook in hierdie variant aangetref. Die gemiddelde getal spesies per monsterperseel is 48 .

Die boomstratum word deur die prominente Protea caffra verteenwoordig. Die gemiddelde hoogte van die bome is $2,5 \mathrm{~m}$ en die gemiddelde kroonbedekking is $20 \%$. Die struikstratum word deur die prominente Diospyros lycioides met 'n gemiddelde hoogte van 1,2 m en 'n gemiddelde kroonbedekking van $7,5 \%$ verteenwoordig.

Die kruidstratum het 'n gemiddelde hoogte van $0,7 \mathrm{~m}$ en 'n gemiddelde kroonbedekking van $40 \%$. Prominente grasspesies soos Trachypogon spicatus, Pogonarthria squarrosa, Tristachya leucothrix, Loudetia simplex, Trichoneura grandiglumis, Themeda triandra en Elionurus muticus word in die variant aangetref. Pentanisia angustifolia, Acalypha angustata, Gnidia capitata, Cyanotis speciosa, Hermannia lancifolia, Tephrosia longipes, Senecio venosus en Lactuca serriola is opvallende niegrasagtige kruide wat in die variant aangeteken is.

1.2 Die Diospyros lycioides - Acacia caffra-boomveld. Die boomveld ${ }^{17}$ word op die middelhange met 'n hoogte van $1500-1570 \mathrm{~m}$ bo seespieël in dic studiegebied aangetref. Dit is laer as die Trachypogon spicatus-Protea caffra-variant geleë. Die goedgedreineerde, dieper $(>0,3 \mathrm{~m})$ grond het geen dagsome nie (figuur 2). Die dominante grondtipe in die plantgemeenskap is die Hutton-, Clovelly- en Glencoegrondvorms. Die diagnostiese plantspesies (spesiegroep 4, tabel 1) van die Diospyros lycioides-Acacia caffra-boomveld is Acacia caffra, Anthospermum hispidulum, Polygala hottentotta, Acacia robusta en Aloe transvaalensis. Spesies van spesiegroepe 5, 7 , $8,10,13$ en 14 is ook in hierdie plantgemeenskap aangeteken (tabel 1). Die gemiddelde aantal spesies per monsterperseel, in die plantgemeenskap, is 35 .

Die prominente bome is Acacia caffra, A. robusta, $A$. karroo en Rhus pyroides. Die boomstratum is goed ontwikkel. Die gemiddelde hoogte van die bome is $4,5 \mathrm{~m}$ en die gemiddelde kroonbedekking is $35 \%$. Die 
struikstratum met 'n gemiddelde hoogte van $1,5 \mathrm{~m}$ en gemiddelde kroonbedekking van $15 \%$ word deur Rhus pyroides en Acacia karroo in struikvorm verteenwoordig. Die twee struikagtige kruide, Protasparagus suaveolens en $P$. laricinus, word ook in die plantgemeenskap aangetref.

Die kruidstratum is swak ontwikkel, met onderskeidelik 'n gemiddelde hoogte en kroonbedekking van $0,5 \mathrm{~m}$ en $50 \%$. Grasspesies wat prominent in die plantgemeenskap is, is Brachiaria serrata, Eragrostis racemosa, Aristida congesta, Rhynchelytrum repens, Trichoneura grandiglumis, Eustachys paspaloides, Elionurus muticus en Cynodon dactylon. Prominente kruide is Anthospermum hispidulum, Polygala hottentotta, Aloe transvaalensis, Cyanotis speciosa, Helichrysum nudifolium, Hermannia depressa, Helichrysum rugulosum, Teucrium trifidum, Lactuca serriola en Senecio venosus.

Spesiegroep 5 toon die floristiese verwantskap tussen die Loudetia simplex-Trachypogon spicatus-grasveld en Diospyros lycioides-Acacia caffra-boomveld. In die ordening (figuur 4) word die verwantskap ook aangedui. Die verwantskap van die Diospyros lycioidesAcacia caffra-boomveld met die laerliggende plantgemeenskappe word met spesiegroep 13 aangedui.

1.3 Die Schizachyrium sanguineum-Vangueria infaustastruikveld.
Die struikveld word op relatief hoogliggende kwartsietdagsome aangetref. Hoewel die struikveld relatief hoërliggend is, is dit laer geleë as die hoogliggende Trachypogon spicatus-Loudetia simplex-grasveld (figuur 3). Die grond is gewoonlik vlak $(<0,3 \mathrm{~m})$ en die dominante grondtipe is die Mispah- en Glenrosagrondvorms (figuur 3). Die dreinering van die grond is goed. Spesiegroep 6 (tabel 1) sluit die diagnostiese spesies van die plantgemeenskap in, naamlik Schizachyrium sanguineum, Vangueria infausta, Rhus magalismontana, Pellaea calomelanos en Zanthoxylum capense. Die gemiddelde getal plantspesies per monsterperseel is 41 .

Die boomstratum is swak ontwikkel met 'n gemiddelde hoogte van 4,5 m en 'n gemiddelde kroonbedekking van $10 \%$. Enkele bome van Acacia karroo verteenwoordig die boomstratum.

Die struikstratum is goed ontwikkel met prominente struike Vangueria infausta, Zanthoxylum capense, Diospyros lycioides en die dwergstruik Rhus magalismontana. Die twee struikagtige kruide Protasparagus suaveolens en $P$. laricinus word ook in hierdie plantgemeenskap aangetref. Die gemiddelde hoogte van die struike is $2,7 \mathrm{~m}$ en die gemiddelde kroonbedekking is $20 \%$.

Die kruidstratum se gemiddelde hoogte is $0,7 \mathrm{~m}$ en
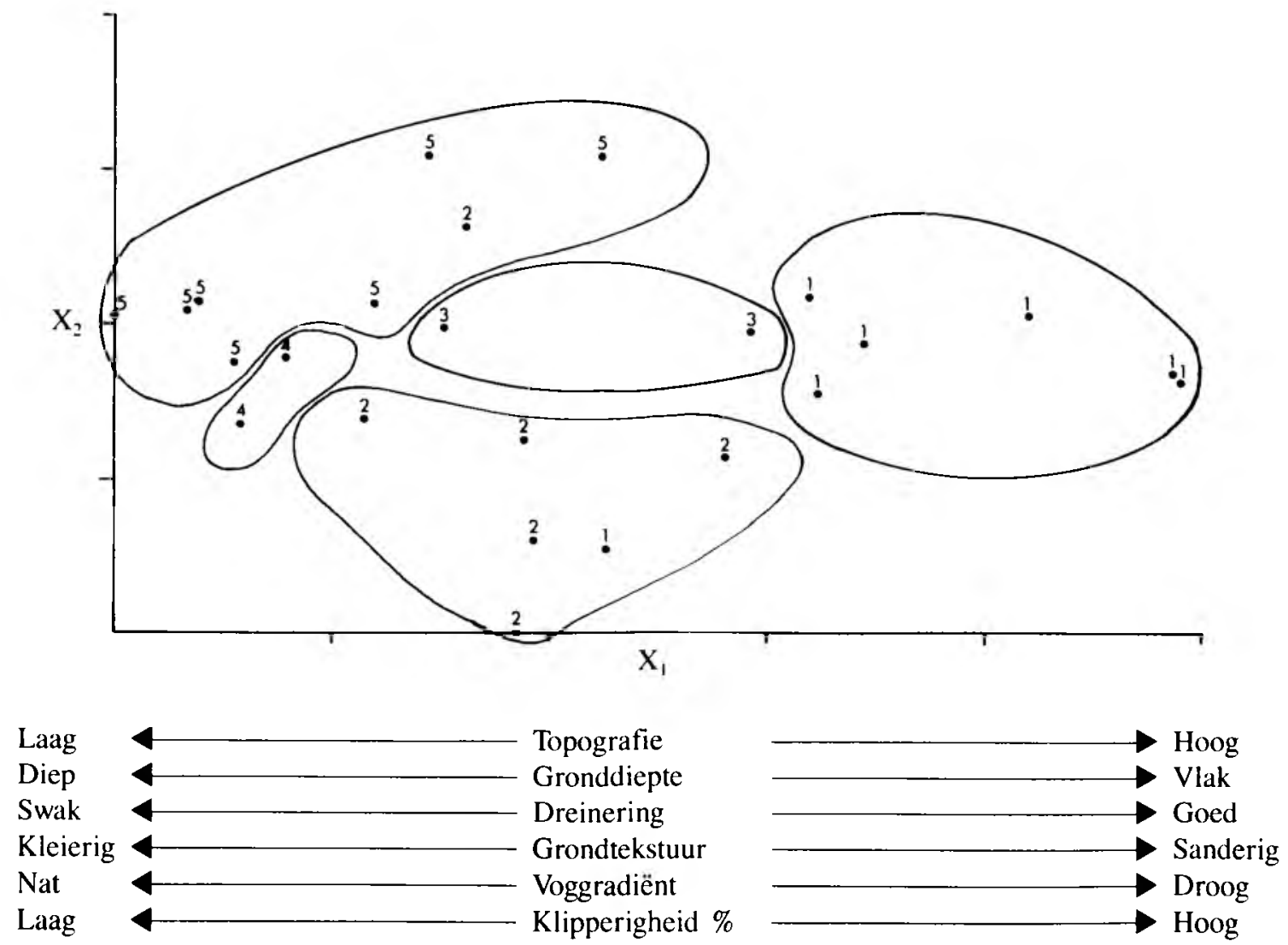

1 - Loudetia simplex-Trachypogon spicatus-grasveld

2 - Diospyros lycioides-Acacia caffra-boomveld

3 - Schizachyrium sanguineum-Vangueria infausta-struikveld

4 - Grewia flava-Acacia karroo-boomveld

5 - Hyparrhenia hirta-Eragrostis plana-grasveld

FIGUUR 4: Die verspreiding van die onderskeie plantgemeenskappe langs die eerste en tweede asse van ordening, met geassosieerde habitatgradiënte teen die eerste as. 
die gemiddelde kroonbedekking is $40 \%$. Die prominente grasse wat in die geneenskap aangeteken is, is Schizachyrium sanguineum, Trichoneura grandiglumis, Aristida congesta, Rhynchelytrum repens, Loudetia simplex, Eustachys paspaloides en Cynodon dactylon. Die nie-grasagtige kruide is Pellaea calomelanos, Helichrysum nudifolium, Tephrosia longipes, Commelina africana. Dicoma anomala en Indigofera comosa.

Spesies van spesiegroepe 7 en 8 dui op 'n floristiese verwantskap tussen dic Loudetia simplex-Trachypogon spicatus-grasveld, Diospyros lycioides-Acacia caffraboomveld en Schizachyrium sanguineum-Vangueria infausta-struikveld. In die ordening (figuur 4) is hierdie plantgemeenskappe hoofsaaklik aan die regterkant van die strooiingsdiagram geplaas. Hierdie verspreiding beklemtoon die verwantskappe met die hoogliggende plantgemeenskappe.

1.4 Die Grewia flava-Acacia karroo-boomveld.

Op die vloedvlaktes word die Grewia flava-Acacia karroo-boomveld aangetref. Die dominante grondtipe is die Westleigh-, Clovelly-en Glencoegrondvorms. Die diagnostiese spesies van dic plantgemeenskap (spesiegroep 9, tabel 1) is Grewia flava, Monsonia angustifolia, Hibiscus pusillus, Crabbea angustifolia en Tarchonanthus camphoratus. Spesies van spesiegroepe $10,12,13$ en 14 is ook in dic plantgemeenskap aan geteken. Die gemiddelde getal plantspesies per monsterperseel is 35 .

Die boomstratum is goed ontwikkeld met Acacia karroo, Tarchonanthus camphoratus en Rhus pyroides die prominente spesies. Die gemiddelde hoogte van die boomstratum is $5,5 \mathrm{~m}$ en die gemiddelde kroonbedekking is $35 \%$. Die struikstratum met 'n gemiddelde hoogte van $1,9 \mathrm{~m}$ en 'n gemiddelde kroonbedekking van 20\%, met die prominente struik Grewia flava asook die struikvorm van Acacia karroo, is goed ontwikkeld. Die dwergstruik Ziziphus zeyheriana is geneig om lokaal in die plantgemeenskap te verdig. Die twee struikagtige kruide, Protasparagus suaveolens en $P$. laricinus, is prominent in die plantgemeenskap.

Die kruidstratum is swak ontwikkeld met ' $\mathrm{n}$ gemiddelde hoogte van $0,55 \mathrm{~m}$ en 'n gemiddelde kroonbedekking van slegs 17\%. Die prominente grasse is Eustachys paspaloides, Eragrostis plana, Hyparrhenia hirta. Digitaria eriantha, Setaria sphacelata, Eragrostis curvula, Themeda triandra en Elionurus muticus. Die prominente nie-grasagtige kruide is Monsonia angustifolia, Hibiscus pusillus, Crabbea angustifolia. Scabiosa columbaria, Hermannia depressa. Sida dregei, Chamaesyce hirta en Teucrium trifidum.

1.5 Die Hyparrhenia hirta-Eragrostis plana-grasveld.

Hierdie grasveld word op die relatief laerliggende, swakgedreineerde waterbane aangetref (figure 2 en 3 ). Die dominante grondvorm is Rensburg. Spesiegroep 1l (tabel 1) bevat die diagnostiese spesies van die plantgemeenskap, naamlik Eragrostis plana en Hyparrhenia hirta. Die plantegroei van die waterbane van die studiegebied is arm aan spesies. Die gemiddelde getal spesies is 22 per monsterperseel, terwyl die gemiddelde hoeveelheid spesies vir die ander plantgemeenskappe 39 per monsterperseel is. Spesies van spesiegroepe 12, 13 en 14 is ook in die plantgemeenskap aangeteken.

Die boom-en struikstratum is in hierdie grasveld af- wesig. Die kruidstratum is goed ontwikkeld met 'n gemiddelde hoogte van $0,9 \mathrm{~m}$ en 'n gemiddelde kroonbedekking van $75 \%$. Die prominente grasse is Eragrostis plana, Hyparrhenia hirta, Digitaria eriantha, Setaria sphacelata, Eragrostis curvula, Themeda triandra en Cynodon dactylon. Die opvallende nie-grasagtige kruide is Scabiosa columbaria. Chamaesyce hirta, Hermannia depressa, Helichrysum rugulosum, Sida dregei en Lactuca serriola. Die dwergstruik Ziziphus zeyheriana is ook hier geneig om lokaal voor te kom. Die waterbane is geskik vir beweiding, is meestal naby water en word dikwels oorbewei.

\section{ORDENING}

Die verspreiding van die relevès langs die eerste en tweede asse van die ordening word in figuur 4 aangedui. Hoewel geen duidelike diskontinuiteit in die verspreiding van die relevès waargeneem kan word nie, is die onderskeie plantgemeenskappe tog tot sekere streke in die strooiingsdiagram beperk. Die opeenvolging van die plantgemeenskappe langs die eerste as van die ordening (figuur 4) kan geassosicer word met gradiënte in topografiese posisies, gronddiepte, grondtekstuur, dreinering en klipperigheid van die grondoppervlak.

Die plantgemeenskappe wat na regs op die strooiingsdiagram geleë is, kom op hoogliggende, goedgedreineerde. vlak, sanderige grond voor. Daarenteen is die plantgemeenskappe wat na heel links op die diagram geleë is, geassosieer met 'n relatief laagliggende habitat met swakker gedreineerde, kleierige grond. Hierdie gradiënt in habitat is dus geassosieer met die gradiënt in plantegroei en is ook in ooreenstenming met die habitatinterpretasie wat in figuur 3 aangedui word.

\section{GEVOLGTREKKING}

Ten spyte van die relatiewe min naturlike plantegroei wat op die Ba-landtipe aangetref word, is die plantgemeenskappe wat onderskei is, ekologies verantwoordbaar en vorm dit ' $n$ basis vir plantegroeibestuurseenhede in dic Mooirivieropvanggebied. Die studie beklemtoon die belang van geologie, topografie (topografiese posisie) en grondtipe vir die afbakening van plantgemeenskappe en derhalwe ook plantegroeibestuurseenhede vir boerdery of natuurbewaring. Die ondersoek lewer ook 'n bydrac tot die beoogde sintese wat 'n onvattende hiërargiese klassifikasic van die grasveldbioom ten doel het.

\section{Erkenning}

Die SNO word bedank vir finansiële steun om die projek te kon uitvoer.

Mev. D. Bezuidenhout, Dept. Plantkunde, Universiteit van Pretoria word bedank vir haar positiewe kommentaar op die manuskrip en ook die opstel van die figure.

\section{LITERATUURVERWYSINGS}

1. Mentis, M.T. \& Huntley, B. (1982). A description of the Grassland Biome Project, S. Afr. Nat. Sci. Prog. Report, 62 (CSIR. Pretoria).

2. Landtipe-opnamepersoneel. (1984). Landtipes van die kaarte 2626 Wes-Rand, 2726 Kroonstad, Memoirs oor die Naluurlike Lamelbouhulpbromne van Suid-Afrika, 4. 1-441

3. Bezuidenhoul. H. \& Bredenkamp. G.J. (1990)). A reconnaissance survey of the vegetation of the dolomitic region in the Potchefstroom 
- Ventersdorp - Randfontein area, South Africa, Phyocoenologia, 18(2/3), 387-403.

4. Bosch. O.J.H. \& Janse van Rensburg, F.P. (1987). Ecological status of species on grazing gradients on shallow soils of the western grassland biome in South Africa. J. Grassl. Soc. South. Afr. , 4, 143-147.

5. Bezuidenhout, H. (1988). in Plamtsosiologiese studic van die Mooirivieropvanggebied, Transwal (M.Sc.-verhandeling. PU vir CHO, Potchefstroom)

6. Edwards. D. (1972). Botanical survey and agriculture, Proceedings of the Grassland Society of South Africa, 7, 15-19.

7. Schulze, R.E. \& McGee. O.S. (1978). Climate indices and classifications in relation to the biogeography of southern Africa. In Biogeography and ecology of southern Africa, Werger, M.J.A. ed. Vol. 1 (Junk, The Hague) p. 240.

8. Van Wyk, S. (1983). 'n Plantekologiese studie van die Abe Bailevnaruurresenaar (M.Sc.-verhandeling, $\mathrm{PU}$ vir $\mathrm{CHO}$, Potchefstroom).

9. Weerburo. (1988). Klimaat van Suid-Afrika, Staatsdrukker, Pretoria, WB $40,1-475$.

10. Bezuidenhout. H. \& Bredenkamp, G.J. (1991). Plantegroeiklassifikasie van die A-landtipe van die Mooirivieropvanggebied. Transvaal, S. A. Tydskr. Natuurwet. en Tegnol., 10, 4-11.

11. Louw, W.J. (1951). An ecological account of the vegetation of the Potchefstroom area, Mem. Bot. Surv. S. Afr., 24, 1-105.

12. Acocks, J.P.H. (1975). Veld types of South Africa, Mem. Bot. Surv: S. Afr., 40, 1-128.

13. Westhoff, V. \& Van der Maarel, E. (1978). The Braun-Blanquet approach. In Classification of plant communities, Whitlaker, R.H. ed. (Junk, The Hague) p. 399.

14. Mueller-Dombois, D. \& Ellenberg, H. (1974). Aims and methods of vegetation ecology (Wiley, New York).

15. Hill, M.O. (1979). TWINSPAN - a Fortran program for arranging multivariate data in an ordered two way table by the classification of individuals and attributes (Cornell University, Ithaca, New York).

16. MacVicar, C.N., Loxton, R.F., Lambrechts, J.J.N., Le Roux, J., De Villiers, J.M., Verster, E., Merryweather, F.R., Van Rooyen, T.H. \& Harmse H.J. Von M. (1977). Grondklassifikasie, 'n binomiese sisreen vir Suid-Afrika (Staatsdrukker, Pretoria).

17. Edwards, D. (1983). A broad-scale structural classification of vegetation for practical purposes, Bothalia, 14, 3 \& 4, 705-812.

18. De Beer, A.S. (1988). Plantspesievoorkeure van vleisbeeste in die Hoêveldstreek onder 'n stelsel ran beheerde selektiewe beweiding (M.Sc.(Agric)-verhandeling, Universiteit van Pretoria, Pretoria).

19. Gibbs Russell, G. E., Reid, C. Van Rooyen, J. \& Smook. L. (1985). List of Species of Southern African Plants. Edition 2. Part 1, Mem. Bot. Surv: S. Afr., 51, 1-152.

20. Gibbs Russell, G.E., Welman, W.G., Retief, E., Immelman, K.L., Germishuizen, G., Pienaar, B.J., Van Wyk, M., Nicholas, A., De Wet, C., Mogford, J.C. \& Mulvena. J. (1987). List of Species of Southern African Plants. Edition 2. Part 2, Mem. Bot. Surv. S. Afr., 56. $1-270$.

21. Hill, M.O. (1979). DECORANA - A Fortran program for detrended correspondence analysis and reciprocal averaging (Cornell University, lthaca, New York).

22. Barkman, J.J., Moravec, J. \& Rauschert, S. (1986). Code of phytosociological nomenclature, 2nd edition, Vegetatio, 67, 145-195.

23. Scheepers, J.C. (1987). Grassland Biome Project: Proceedings of the workshop on classification and mapping, Occasional Report. 16, 1-31 (CSIR, Pretoria).

24. Kooij, M.S., Bredenkamp, G.J. \& Theron, G.K. (in press). A phytosociological survey of the north - western Orange Free State. 1. The physical environment, Bothalia.

25. Kooij. M.S., Bredenkamp, G.J. \& Theron, G.K. (in press). A phytosociological survey of the north - western Orange Free State. 2. The D land type, Bothalia. 